\title{
Exploring All Avenues for Radiotherapy in Oligorecurrent Prostate Cancer Disease Limited to Lymph Nodes: A Systematic Review of the Role of Stereotactic Body Radiotherapy
}

\author{
Elisabetta Ponti ${ }^{a}$, Andrea Lancia $^{a}$, Piet Ost $^{b}$, Fabio Trippa $^{c}$, Luca Triggiani $^{d}$, \\ Beatrice Detti ${ }^{e}$, Gianluca Ingrosso ${ }^{a, *}$ \\ ${ }^{a}$ Department of Radiation Oncology, Policlinico Tor Vergata, University, Rome, Italy; ${ }^{\mathrm{b}}$ Department of Radiotherapy, Ghent University Hospital, Ghent, \\ Belgium; ' ${ }^{\mathrm{C}}$ Department of Radiation Oncology, 'S. Maria' Hospital, Terni, Italy; ${ }^{\mathrm{d}}$ Department of Radiation Oncology, University and Spedali Civili Hospital,

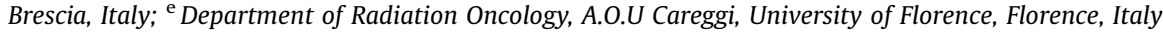

Article info

Associate Editor: James Catto

\section{Keywords:}

Oligorecurrent prostate cancer Lymph node metastasis Stereotactic body radiotherapy Local control

Progression-free survival Androgen-deprivation free survival

\begin{abstract}
Context: Stereotactic body radiotherapy (SBRT) is emerging as a treatment option in patients affected by oligorecurrent prostate cancer disease limited to lymph nodes, a subgroup of patients who would otherwise be treated only with androgen deprivation therapy (ADT).

Objective: To perform a systematic review of SBRT for oligorecurrent prostate cancer limited to lymph nodes.

Evidence acquisition: We performed a systematic review of PubMed/Medline in October 2016 according to the Preferred Reporting Items for Systematic Review and Meta-analysis (PRISMA). We searched for studies reporting on biochemical or clinical progression and/or toxicity or complications of SBRT. Reports were excluded if these end points could not be ascertained or separately analyzed, or if insufficient details were provided.

Evidence of synthesis: A total of 363 patients from nine studies were collected. Of these patients, 211 were treated with SBRT for a total of 270 lymph nodes. With an alpha-beta ratio of $3 \mathrm{~Gy}$, the biologically effective dose in fractionated SBRT was $>100 \mathrm{~Gy}$ in all studies (range, 88-216 Gy). With a median follow-up of $19.23 \mathrm{mo}$, local control was achieved in $98.1 \%$ of patients. Median progression-free survival (defined as biochemical and/or radiological progression) was $22.5 \mathrm{mo}$ (range, 11-30 mo). Information about ADT during SBRT was available in 281 patients, of whom $114(40.5 \%)$ were on ADT during SBRT, and the duration of hormone therapy ranged from 1 to 17.5 mo. Median ADT-free survival was $32.8 \mathrm{mo}$ (range, 25-44 mo). About toxicity, Common Terminology Criteria for Adverse Events toxicity scale was most used. Acute and/or late grade $\geq 2$ toxicity was reported in only $5.6 \%$ of patients, and no patient developed grade 4 toxicity.

Conclusions: SBRT seems to be promising in lymph node oligorecurrent prostate cancer, although there is a weak level of evidence to support such investigational treatment, which is currently based on retrospective studies of single-institution or pooled experiences. ADT-free survival is an interesting end point, which needs to be investigated. Patient summary: We performed a systematic review to assess outcomes and toxicity of stereotactic body radiotherapy (SBRT) for patients affected by oligorecurrent prostate cancer limited to lymph nodes. We concluded that SBRT is a promising therapy in this setting, but it needs to be validated in randomized controlled trials.
\end{abstract}

(c) 2017 European Association of Urology. Published by Elsevier B.V. All rights reserved.

\footnotetext{
* Corresponding author. Department of Radiation Oncology, Policlinico Tor Vergata, University, Rome, Italy. Tel. +390620904300; Fax: +390620904332.

E-mail address: ingrosso.gianluca@gmail.com (G. Ingrosso).
}

http://dx.doi.org/10.1016/j.euf.2017.07.006

2405-4569/@ 2017 European Association of Urology. Published by Elsevier B.V. All rights reserved. 


\section{Introduction}

Stereotactic body radiotherapy (SBRT) is emerging as an appropriate treatment option in patients affected by limited metastatic disease, defined as "oligometastatic state," which is considered as an intermediate state between localized and widespread cancer, and seems to be characterized by a unique biological profile [1]. In such patients with a limited number of metastases $(<3$ or $<5)$ from a variety of primary sites, it seems that local therapy (surgery or ablative radiotherapy) might improve overall survival and disease progression-free survival (PFS), and delay the need for systemic therapy [2-6]. In this therapeutic scenario, SBRT seems to be a safe treatment option with a very low toxicity profile, and without the morbidity and risk associated with surgical procedures [7].

In oligorecurrent prostate cancer patients, who eventually develop a low burden of disease after curative treatment, SBRT could mean an appropriate therapeutic strategy with curative intent. SBRT could also defer palliative androgen deprivation therapy (ADT), which is currently the standard of care for such patients, despite the fact that it can have a detrimental effect on their quality of life. The subset of prostate cancer patients with oligorecurrence confined to lymph nodes represents a very early metastatic setting in which local treatment such as SBRT might have a great impact on disease control [8-10].

The aim of our study was to review the available literature on SBRT for lymph node recurrent prostate cancer patients, in order to evaluate efficacy and toxicity of this high-precision noninvasive ablative treatment in such an early metastatic setting. In the Discussion section, we also provide an analysis of the major studies investigating the role of prophylactic irradiation of regional lymph nodes in the same setting of patients.

\section{Evidence acquisition}

We searched for articles reporting on oncological outcome (biochemical response and/or PFS) and toxicity of prostate cancer patients, affected by oligorecurrent disease limited to lymph nodes and treated with SBRT. SBRT was defined as a radiotherapy dose of at least $5 \mathrm{~Gy}$ per fraction to a biologically effective dose of $80 \mathrm{~Gy}$ with an alpha-beta ratio of 3 Gy. A PubMed literature search was conducted using the Preferred Reporting Items and Meta-Analyses (PRISMA) [11]. We identified articles published within the last $10 \mathrm{yr}$ up to September 30, 2016, using Medline search with the following selection criteria: English language, full papers, oligorecurrent prostate cancer limited to lymph nodes treated with SBRT, and oncological and toxicity data available. The following Medline terms were used: prostate cancer, lymph node metastasis, lymph node recurrence, oligometastatic prostate cancer, oligorecurrent prostate cancer, stereotactic radiotherapy, stereotactic body radiotherapy, radiosurgery, and stereotactic ablative radiotherapy. If multiple publications from the same center were available, the most recent one was selected. We reviewed the full version of each article. The following information was abstracted from all primary reports: primary author, reference, year of publication, number of patients, patient population, age, number of patients treated with SBRT for node metastasis, number of irradiated metastases, study design, treatment of the primary prostate cancer, dose and fractionation of SBRT, oncological outcome (PFS and overall survival), local control, prognostic factors (univariate and multivariate), and toxicity.

\section{Evidence synthesis}

The flowchart of the systematic review is reported in Fig. 1. In total, 363 patients from nine studies [12-20] were collected (Table 1 ). Of these patients, 211 were treated with SBRT for a total of 270 lymph nodes (Table 2). In Table 3, we reported the site (pelvic or extrapelvic) of nodes irradiated with SBRT: 162 (76.7\%) patients were affected by pelvic oligorecurrence. Information about the primary treatment was available in 334 (92\%) patients: 250 (75\%) underwent radical prostatectomy \pm radiotherapy \pm ADT, 78 (23.3\%) underwent radiotherapy $\pm \mathrm{ADT}$, and six (1.7\%) received chemotherapy as primary treatment.

Median time from primary treatment to oligorecurrent disease was available only in seven studies (Table 1 ), with an overall median value of 37.45 mo (range, 11.5-75.6 mo). Choline-positron emission tomography (PET)/computed tomography (CT) was used in almost all studies to detect disease in patients with biochemical recurrence after primary treatment. The median prostate-specific antigen (PSA) value at oligorecurrent disease, available in six studies, was $4.2 \mathrm{ng} / \mathrm{ml}$ (range, $1.77-16 \mathrm{ng} / \mathrm{ml}$ ). Median follow up was 21.9 mo (range, 4.4-36 mo).

SBRT was delivered with a linear accelerator in almost all studies (Table 2). Several radiotherapy schedules were used, varying from 5 to $11 \mathrm{~Gy}$ per fraction, to a total dose of 25-50 $\mathrm{Gy}$, whereas four metastatic nodes were irradiated using a single fraction (range, 12-24 Gy). With an alpha-beta ratio of $3 \mathrm{~Gy}$, the biologically effective dose in fractionated SBRT was $>100 \mathrm{~Gy}$ in all studies (range, 88-216 Gy). The median gross tumor volume-planning target volume margin was $5 \mathrm{~mm}$. In all studies, image guidance was used prior to radiotherapy delivery.

Between studies, biochemical recurrence after SBRT was defined in different ways: some authors considered it as a

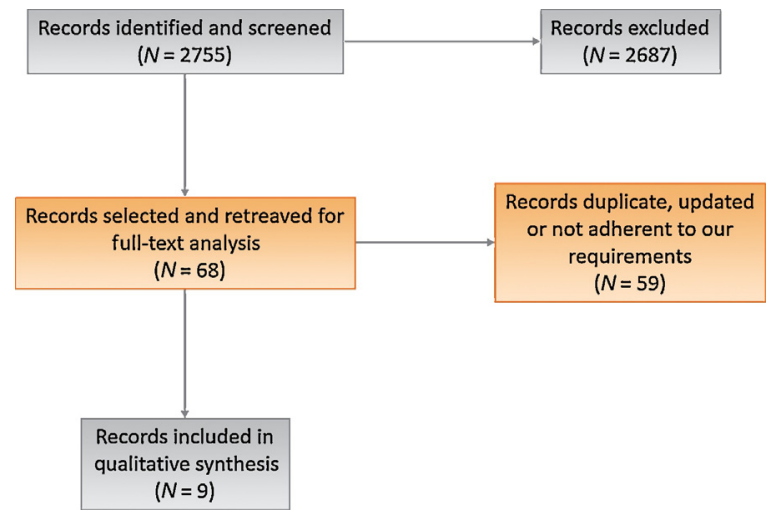

Fig. 1 - Flowchart of the systematic review. 
Table 1 - Patient characteristics.

\begin{tabular}{|c|c|c|c|c|c|c|c|c|c|c|}
\hline Study & $\begin{array}{l}\text { No. of pts } \\
\text { (total) }\end{array}$ & $\begin{array}{c}\text { Age } \\
\text { (median) }\end{array}$ & $\begin{array}{l}\text { No. of } \\
\text { pts treated } \\
\text { for nodes }\end{array}$ & $\begin{array}{l}\text { Median time } \\
\text { to metastatic } \\
\text { recurrence } \\
\quad(\mathrm{mo})\end{array}$ & $\begin{array}{l}\text { Median PSA } \\
\text { at time of node } \\
\text { metastasis } \\
(\mathrm{ng} / \mathrm{ml})\end{array}$ & Staging method & $\begin{array}{l}\text { Median } \\
\text { FU (mo) }\end{array}$ & ADT & $\begin{array}{l}\text { No. of } \\
\text { pts in } \\
\text { ADT }\end{array}$ & $\begin{array}{c}\text { Median } \\
\text { duration of } \\
\text { ADT (mo) }\end{array}$ \\
\hline $\begin{array}{l}\text { Casamassima } \\
\text { et al (2011) [12] }\end{array}$ & 25 & $66^{a}$ & 25 & $11.8-36.7$ & 5.65 & Choline-PET (100\%) & 29 & No & - & - \\
\hline $\begin{array}{l}\text { Jereczek-Fossa et al } \\
\text { (2012) [13] }\end{array}$ & 34 & 68.3 & 18 & 66 (mean) & $1.77 ; 10.7^{\mathrm{b}}$ & Choline-PET (100\%) & $21.9 ; 13.7^{\mathrm{b}}$ & Yes & $14(78 \%)$ & $17.5 ; 12^{b}$ \\
\hline $\begin{array}{l}\text { Ahmed et al (2013) } \\
\text { [14] }\end{array}$ & 17 & 65 & 1 & 50.4 & NR & $\begin{array}{l}\text { Choline-PET (53\%), } \\
\text { MRI ( } 47 \%)\end{array}$ & 4.4 & Yes & $1(100 \%)$ & NR \\
\hline $\begin{array}{l}\text { Decaestecker et al } \\
\text { (2014) [15] }\end{array}$ & 50 & $59^{a}$ & 27 & 57.6 & 5.1 & $\begin{array}{l}\text { Choline-PET (36\%), } \\
\text { FDG-PET }(64 \%)\end{array}$ & 24 & Yes & $35(70 \%)$ & 1 \\
\hline $\begin{array}{l}\text { Detti et al (2015) } \\
\text { [16] }\end{array}$ & 30 & $64^{a}$ & 30 & 75.6 & 16 & Choline-PET (100\%) & 12 & Yes & $14(46 \%)$ & NR \\
\hline $\begin{array}{l}\text { Muldermans et al } \\
\text { (2016) [17] }\end{array}$ & 66 & $61.4^{\mathrm{a}}$ & 5 & NR & NR & $\begin{array}{l}\text { Choline-PET ( } 70 \%) \text {, } \\
\text { MRI (12\%), CT (3\%) }\end{array}$ & 16 & NR & NR & NR \\
\hline $\begin{array}{l}\text { Pasqualetti et al } \\
\text { (2016) [18] }\end{array}$ & 29 & 71.2 & 17 & 11.5 & 3.43 (mean) & Choline-PET (100\%) & 11.5 & No & - & - \\
\hline $\begin{array}{c}\text { Ingrosso et al } \\
\text { (2016) [19] }\end{array}$ & 40 & 74 & 40 & 37.4 & 4.2 & Choline-PET (100\%) & 23.8 & Yes & $19(47 \%)$ & NR \\
\hline $\begin{array}{l}\text { Ost et al (2016) } \\
\text { [20] }\end{array}$ & 72 & $60^{a}$ & 72 & 44.4 & 3.4 & $\begin{array}{l}\text { Choline-PET ( } 75 \%), \\
\text { FDG-PET ( } 24 \%), \\
\text { MRI }(1 \%)\end{array}$ & 36 & Yes & 31 (43\%) & 1 \\
\hline $\begin{array}{l}\text { ADT = androgen dep } \\
\text { tomography; } \mathrm{PSA}= \\
\text { a Mean value. } \\
\text { b Two patients with }\end{array}$ & $\begin{array}{l}\text { ation the } \\
\text { state-spe }\end{array}$ & $\begin{array}{l}y \text {; FDG }= \\
\text { antigen }\end{array}$ & $\begin{array}{l}\text { leoxyglu } \\
\text { s = patie } \\
\text { stasis. }\end{array}$ & & & & & & & \\
\hline
\end{tabular}

Table 2 - Treatment characteristics.

\begin{tabular}{|c|c|c|c|c|c|c|c|c|c|}
\hline Study & $\begin{array}{l}\text { No. of } \\
\text { nodes } \\
\text { (total) }\end{array}$ & $\begin{array}{c}\text { No. of } \\
\text { pts treated with } \\
\text { SBRT for node } \\
\text { metastases }\end{array}$ & $\begin{array}{l}\text { No. of nodes } \\
\text { treated with } \\
\text { SBRT }\end{array}$ & $\begin{array}{l}\text { Median } \\
\text { GTV (cc) }\end{array}$ & $\begin{array}{l}\text { Median } \\
\text { GTV-PTV } \\
\text { margin } \\
(\mathrm{mm})\end{array}$ & $\begin{array}{l}\text { Linac/Cyber } \\
\text { knife }\end{array}$ & SBRT schedule & $\begin{array}{c}\text { Dose } \\
\text { prescription }\end{array}$ & $\begin{array}{c}\text { BED } \\
(\alpha / \beta=3)\end{array}$ \\
\hline $\begin{array}{l}\text { Casamassima et al } \\
\text { (2011) [12] }\end{array}$ & 25 & 18 & 18 & NR & 5 & Linac & $3 \times 10 \mathrm{~Gy}$ & $\begin{array}{l}\text { To the isodose } \\
\text { covering 95\% of } \\
\text { the PTV }\end{array}$ & 130 \\
\hline $\begin{array}{l}\text { Jereczek-Fossa et al } \\
\text { (2012) [13] }\end{array}$ & 18 & 18 & 18 & NR & 2 & Cyber & $\begin{array}{l}3 \times 11 \text { Gy; } \\
3 \times 12 \text { Gy } \\
(\text { in } 2 \text { pts } \mathrm{M} 1 \text { ) }\end{array}$ & $\begin{array}{l}\text { To the mean } 80 \% \\
\text { isodose }\end{array}$ & $154-165$ \\
\hline $\begin{array}{l}\text { Ahmed et al (2013) } \\
{[14]}\end{array}$ & 1 & 1 & 1 & NR & 5 & Linac & $5 \times 10 \mathrm{~Gy}$ & NR & 130 \\
\hline $\begin{array}{l}\text { Decaestecker et al } \\
\text { (2014) [15] }\end{array}$ & 27 & 27 & 27 & NR & 3 & Linac & $\begin{array}{l}3 \times 10 \mathrm{~Gy} \\
5 \times 10 \mathrm{~Gy}\end{array}$ & $\begin{array}{l}80 \% \text { of the } \\
\text { prescribed dose } \\
\text { covering } 90 \% \text { of } \\
\text { the PTV }\end{array}$ & $130-133$ \\
\hline $\begin{array}{l}\text { Detti et al (2015) } \\
\quad[16]\end{array}$ & 39 & 30 & 39 & NR & 2 & Cyber & $\begin{array}{l}1 \times 24 \mathrm{~Gy} \\
5 \times 6 \mathrm{~Gy} \\
3 \times 9 \mathrm{~Gy} \\
3 \times 10 \mathrm{~Gy} \\
3 \times 12 \mathrm{~Gy}\end{array}$ & NR & $180-216$ \\
\hline $\begin{array}{l}\text { Muldermans et al } \\
\text { (2016) [17] }\end{array}$ & 6 & 5 & 6 & NR & 5 & Linac & $\begin{array}{l}1 \times 24 \mathrm{~Gy} \\
1 \times 16 \mathrm{~Gy} \\
5 \times 10 \mathrm{~Gy} \\
3 \times 10 \mathrm{~Gy}\end{array}$ & AAPM 101 & $101-133$ \\
\hline $\begin{array}{l}\text { Pasqualetti et al } \\
\text { (2016) [18] }\end{array}$ & 25 & NR & 25 & 2.9 (mean) & 3 & Linac & $\begin{array}{l}1 \times 24 \mathrm{~Gy} \\
3 \times 9 \mathrm{~Gy}\end{array}$ & $\begin{array}{l}\text { To the periphery } \\
\text { of the target }\end{array}$ & 64.8-129.6 \\
\hline $\begin{array}{l}\text { Ingrosso et al } \\
\text { (2016) [19] }\end{array}$ & 47 & 40 & 47 & 3 & $5-8$ & Linac & $\begin{array}{l}1 \times 12 \mathrm{~Gy} \\
5 \times 10 \mathrm{~Gy} \\
5 \times 8 \mathrm{~Gy} \\
4 \times 8 \mathrm{~Gy} \\
5 \times 7 \mathrm{~Gy} \\
5 \times 6 \mathrm{~Gy} \\
5 \times 5 \mathrm{~Gy}\end{array}$ & $\begin{array}{l}95 \% \text { of the dose } \\
\text { to the } 95 \% \text { of the } \\
\text { PTV }\end{array}$ & $36-130$ \\
\hline $\begin{array}{l}\text { Ost et al (2016) } \\
{[20]}\end{array}$ & 89 & 72 & 89 & NR & $2-7$ & Linac/Cyber & $\begin{array}{l}3 \times 10 \mathrm{~Gy} \\
3 \times 8 \mathrm{~Gy} \\
5 \times 6 \mathrm{~Gy} \\
10 \times 5 \mathrm{~Gy}\end{array}$ & NR & $88-140$ \\
\hline
\end{tabular}

BED = biologically effective dose; GTV = gross tumor volume; NR = not reported; pts = patients; PTV = planning target volume; SBRT = stereotactic body radiotherapy. 
Table 3 - Site (pelvic or extrapelvic) of nodes treated with SBRT.

\begin{tabular}{|c|c|c|c|c|}
\hline & $\begin{array}{c}\text { Total no. of patients } \\
\text { treated with } \\
\text { SBRT }\end{array}$ & $\begin{array}{c}\text { Total no. of nodes } \\
\text { treated with } \\
\text { SBRT }\end{array}$ & $\begin{array}{c}\text { Pelvic } \\
\text { (no. of pts/no. of nodes) }\end{array}$ & $\begin{array}{l}\text { Extrapelvic (no. of } \\
\text { pts/no. of nodes) }\end{array}$ \\
\hline Casamassima et al (2011) [12] & 18 & 18 & 15 (pelvic and/or extrapelvic)/NR & 3 (mediastinal)/NR \\
\hline Jereczek-Fossa et al (2012) [13] & 18 & 18 & $16 / 16$ & $2 / 2$ \\
\hline Ahmed et al (2013) [14] & 1 & 1 & 0 & $1 / 1$ \\
\hline Decaestecker et al (2014) [15] & 27 & 27 & $25 / 25$ & $2 / 2$ \\
\hline Detti et al (2015) [16] & 30 & 39 & $\mathrm{NR} / 27$ & $\mathrm{NR} / 12$ \\
\hline Muldermans et al (2016) [17] & 5 & 6 & NR & NR \\
\hline Pasqualetti et al (2016) [18] & NR & 25 & $\mathrm{NR} / 18$ & $\mathrm{NR} / 7$ \\
\hline Ingrosso et al (2016) [19] & 40 & 47 & $35 / 40$ & $5 / 7$ \\
\hline Ost et al (2016) [20] & 72 & 89 & $53 / \mathrm{NR}$ & 19/NR \\
\hline
\end{tabular}

single PSA increase without a cutoff value, while others defined it as two consecutive increases of $\geq 20-25 \%$ compared with the pre-SBRT value, or simply two consecutive increases. Radiological PFS was defined as the presence of new metastases after SBRT, or the presence of in-field recurrence and/or new metastases. Follow-up evaluation consisted in PSA every 2-3 mo and choline-PET 3-6 mo after SBRT.

Local control was achieved in $98.1 \%$ of patients, and PFS (defined as biochemical and/or radiological progression) ranged between 11 and 30 mo with a median value of 22.5 mo (Table 4). Only in two studies, there was an infield recurrence (for a total of four patients).

Data on concomitant ADT (Table 1) were available in eight studies (in two of them no ADT was combined with SBRT), for a total of 281 patients. Of the 114 (40.5\%) patients who were on ADT during SBRT, the duration of hormone therapy ranged from 1 to 17.5 mo (Table 1 ). ADT-free survival, ranging from 25 to 44 mo with a median value of 32.8 mo (Table 4), was available only in four studies (including 191 patients), and this means that in 106/191 (55.5\%) patients there could be a potential important delay in the start of ADT.

About toxicity, the Common Terminology Criteria for Adverse Events toxicity scale was the most used, whereas Radiation Therapy Oncology Group scale was used in three studies (Table 4 ). Acute and/or late grade $\geq 2$ toxicity was reported in only $5.6 \%$ of patients, and no patient developed grade 4 toxicity. More specifically, two patients experienced acute toxicity $\geq 2[13,19]$ and late toxicity was reported in five patients (three patients with grade 2 and two patients with grade 3 ) $[13,15,19,20]$.

\subsection{Discussion}

Oligorecurrent prostate cancer limited to lymph nodes may be a very favorable clinical condition. The present work underlines the role of ablative SBRT in the management of

Table 4 - Results.

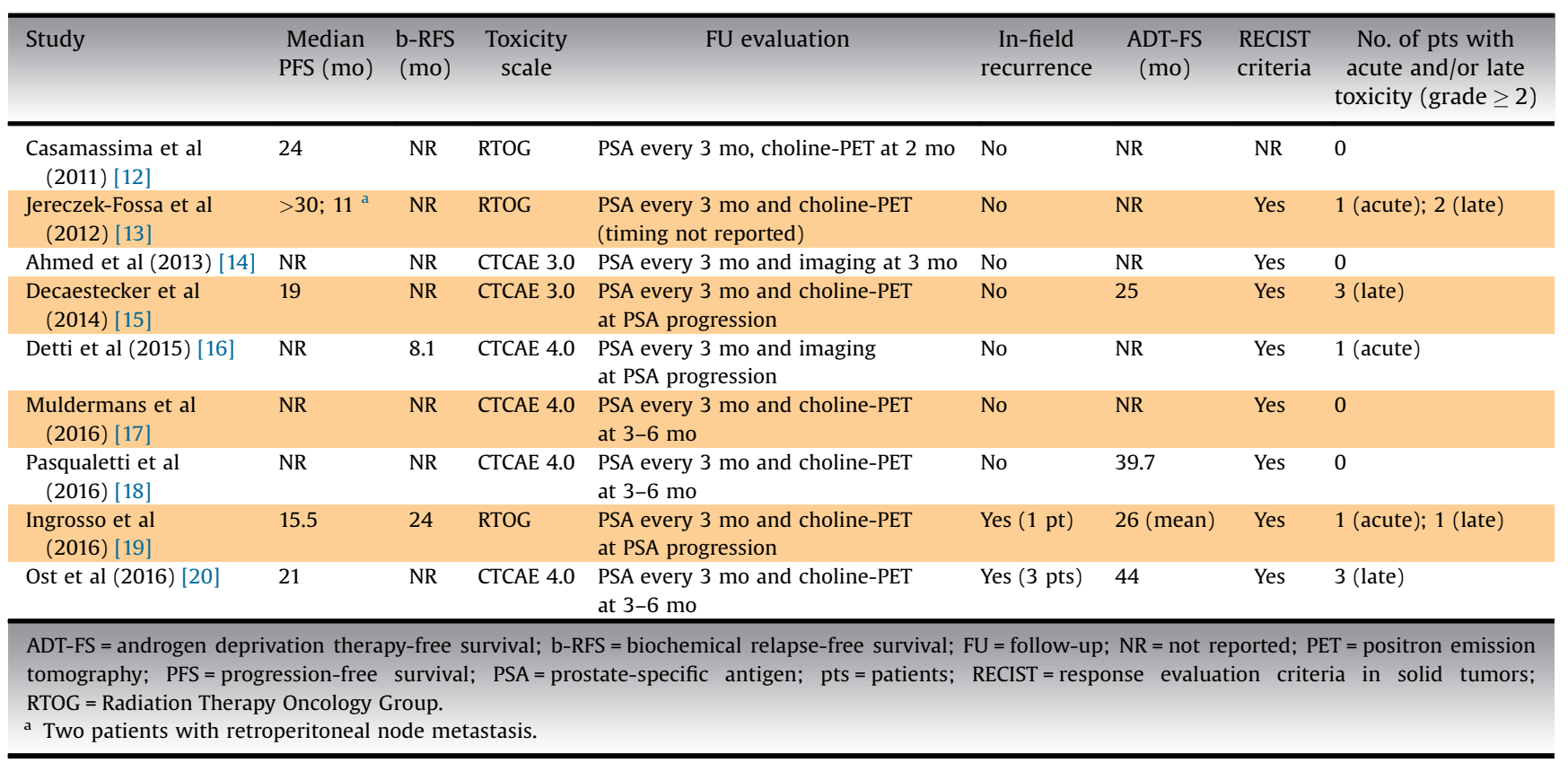


patients affected by lymph node oligorecurrent disease, a subgroup of patients who would otherwise be treated only with delayed or immediate ADT [21], which affects patients' quality of life in multiple spheres.

Choline-PET was the most used staging modality at diagnosis of oligorecurrence. In fact, it was employed in $100 \%$ of cases in five studies and from $36 \%$ to $75 \%$ in the remaining four (Table 1); however, this imaging technique, with either 18F-fluoromethylcholine or 11C-choline, has a low detection rate $[22,23]$ at low PSA levels, a setting in which a targeted salvage therapy might result in better outcome. Currently, many patients being treated with ablative therapy for oligometastatic disease actually have undetectable micrometastases that will cause mainly oligoprogression rather than widespread disease [20]. In a recent retrospective analysis, Ost et al [20] found that after SBRT for nodal prostate cancer oligometastases, the pattern of relapse was mainly nodal and oligometastatic. This modality of progression might give the possibility of a repeated SBRT strategy, similarly to what has been described for brain metastasis stereotactic radiotherapy [24]. In these patients, also the combination of prophylactic regional nodal irradiation and ablative boost to the nodal lesion could be a treatment option. For instance, Rischke et al [25] reported that prophylactic nodal irradiation added to salvage lymph node dissection results in a significant delay of node relapse within the treated region compared with surgery only (5-yr relapse-free rate $70.7 \%$ vs $26.3 \%, p<0.0001$ ). Other studies on prophylactic irradiation on lymph node chains adjacent to PET-positive nodes reported a good outcome with grade $\geq$ toxicity rates ranging from $15 \%$ to $25 \%[26,27]$.

In the recent past, regional lymph node dissection in oligorecurrent prostate cancer limited to lymph nodes has been proposed to reduce disease burden, improve the efficacy of ADT, and delay clinical progression $[28,29]$. In the same way, regional lymph node irradiation, such as whole-pelvis radiotherapy (wpRT), has been evaluated $[26,30,31]$. The series by Schick et al [30] analyzed 43 patients affected by $\leq 4$ metachronous prostate cancer metastatic nodes. More specifically, 21 patients received radiotherapy for pelvic lymph node metastases and five for both pelvic and extrapelvic node metastases. This subset of 26 patients received wpRT (total median dose $50.4 \mathrm{~Gy}$ ) with a boost (total median dose $65 \mathrm{~Gy}$ ) to the choline-PETpositive nodes, in addition to limited ADT (median $12 \mathrm{mo}$ ). At $3 \mathrm{yr}$, biochemical relapse-free survival (b-RFS) was $54.5 \%$, clinical failure-free survival (defined as the time from radiotherapy to the development of new metastases) $58.6 \%$, and overall survival $91.7 \%$. Fodor et al [26] published the results of a phase II trial on choline-PET-guided radiotherapy analyzing $3 \mathrm{yr}$ toxicity and outcome in 83 patients affected by lymph node relapse after primary treatment. Fifty-eight (71.6\%) patients received concomitant/adjuvant ADT for a median time of 12 mo. Regarding radiotherapy, the areas of microscopic involvement included in the clinical target volume were the regional lymph node chains or only the lymphatic chain including choline-PET-positive nodes, depending on overlap with previously irradiated volumes for primary treatment. Seventy-two patients were irradiated at the pelvic and/or lumbar-aortic lymph nodes. The total dose for prophylactic irradiation was $51.8 \mathrm{~Gy}$ in 28 fractions. The total dose in the simultaneous integrated boost of the choline-PET-positive nodes was $65.5 \mathrm{~Gy}$. Threeyear actuarial overall, local relapse-free survival, and clinical relapse-free survival (defined as new metastases) were $80 \%, 89.8 \%$, and $61.8 \%$, respectively. The $3-\mathrm{yr}$ b-RFS was 42.2\%. The presence of extrapelvic lymph node disease and the number of PET-positive nodes negatively influenced clinical relapse. Regarding toxicity, the 3-yr actuarial grade $\geq 2$ rectal and genitourinary toxicities were $6.6 \%$ and $26.3 \%$, respectively. Würschmidt et al [27] reported a 3-yr b-RFS of $49 \%$ and a median survival of 28.3 mo in 19 patients who received wpRT (total dose $45 \mathrm{~Gy}$ in 3D conformal irradiation, $50.4 \mathrm{~Gy}$ in intensity-modulated radiation therapy) with a boost (median total dose 66.6 Gy) to the cholinePET-positive nodes. At 28 mo, $75 \%$ of patients were free from new metastases. In the total cohort, acute and late grade $\geq 2$ toxicities were $15 \%$ and $16 \%$, respectively.

New imaging tools such as 68Ga-PSMA-11 PET could improve the treatment selection by detecting oligorecurrent disease in an early stage or by upstaging an apparent oligorecurrent disease. When compared with 11C-choline PET, 68Ga-PSMA-11 PET demonstrated a significantly higher detection rate of lymph node metastasis $(71 \%$ vs $94 \%, p<0.001$ ) [32]. In particular, its higher detection rate for local relapse, lymph nodes, and bone lesions with respect to $18 \mathrm{~F}$-fluoromethylcholine or $11 \mathrm{C}$-choline PET is more evident at a low PSA value $(<1 \mathrm{ng} / \mathrm{ml})$ [32-34]. Finally, the comparison with histology data revealed high diagnostic accuracy of PSMA-PET (per lesion specificity of 97\% and sensitivity of $80 \%$; per patient specificity and sensitivity both of 86\%) [35]. Other imaging options are whole-body magnetic resonance, which is useful for the detection of bone metastases [36,37] but less suited for lymph node recurrence [38], and magnetic resonance lymphography with iron oxide nanoparticles, which has high sensitivity (65-92\%) and specificity (93-98\%) [39] but is currently not commercially available.

Advances in diagnostic imaging as well as novel biomarkers will lead to a better selection of patients with a low burden of disease, who could be treated only with localized ablative radiotherapy, obviating the need of regional prophylactic nodal irradiation and postponing systemic therapy.

Although SBRT seems to be promising in lymph node oligorecurrent prostate cancer, which is usually a slowly growing tumor, there is a weak level of evidence to support such treatment. In fact, the main limitation of the reported studies in our review is their retrospective nature, based on single-institution or pooled experiences. The other limitation is the small number of patients included in each series. No data on tumor volume were reported in almost all studies.

Ongoing randomized phase 2 clinical trials, such as the STOMP [40] and ORIOLE [41], will assess the impact of ablative radiotherapy in terms of overall survival, PFS, ADT-free survival, and quality of life in patients with $\leq 3$ metastases, compared with the standard of care. Another 
phase 2 trial [42] will address the role of wpRT in patients affected by $\leq 5$ pelvic oligometastases versus ADT.

\section{Conclusions}

The standard treatment option in lymph node oligorecurrent prostate cancer patients is palliative ADT until resistance, but metastasis-directed therapy seems to be promising in this setting, although the optimal salvage treatment needs to be identified by prospective trials. A lower PSA doubling time and a smaller number of metastases could help identify the best candidates for SBRT.

According to retrospectively collected data, SBRT is safe (with toxicity rates ranging from $0 \%$ to $15 \%$ ), achieves high local control rate (near to $100 \%$ ), and has a positive impact on PFS. An interesting end point is ADT-free survival, based on patient-reported compliance to such a truly impactful treatment. Hence, further investigation on this end point is needed.

In the near future, clinical, biological, and genomic features will better define oligorecurrent disease, and this will lead to the stratification of different prognostic classes. It is likely that in selected patients SBRT alone will be the treatment of choice, whereas in other cases there would be a need for treatment intensification.

Author contributions: Gianluca Ingrosso had full access to all the data in the study and takes responsibility for the integrity of the data and the accuracy of the data analysis.

Study concept and design: Ponti, Lancia, Ingrosso.

Acquisition of data: Ponti, Lancia, Ingrosso, Detti.

Analysis and interpretation of data: Ponti, Lancia, Ingrosso, Ost.

Drafting of the manuscript: Ponti, Lancia, Ingrosso, Trippa, Triggiani.

Critical revision of the manuscript for important intellectual content: Ost,

Detti.

Statistical analysis: Ponti, Lancia, Ingrosso, Detti.

Obtaining funding: None.

Administrative, technical, or material support: None.

Supervision: None.

Other: None.

Financial disclosures: Gianluca Ingrosso certifies that all conflicts of interest, including specific financial interests and relationships and affiliations relevant to the subject matter or materials discussed in the manuscript (eg, employment/affiliation, grants or funding, consultancies, honoraria, stock ownership or options, expert testimony, royalties, or patents filed, received, or pending), are the following: None.

Funding/Support and role of the sponsor: None.

\section{References}

[1] Weichselbaum RR, Hellman S. Oligometastases revisited. Nat Rev Clin Oncol 2011;8:378-82.

[2] Staren ED, Salerno C, Rongione A, Witt TR, Faber LP. Pulmonary resection for metastatic breast cancer. Arch Surg 1992;127:1282-4.

[3] Fong Y, Cohen AM, Fortner JG, et al. Liver resection for colorectal metastases. J Clin Oncol 1997;15:938-46.

[4] Tomlinson T, Robinson LA, Shell MJ, et al. Outcomes of adrenalectomy for isolated synchronous versus metachronous adrenal metastases in non-small-cell lung cancer: a systematic review and pooled analysis. J Clin Oncol 2008;26:1142-7.
[5] Hoyer M, Roed H, Traberg Hansen A, et al. Phase II study on stereotactic body radiotherapy of colorectal metastases. Acta Oncol 2006;45:823-30.

[6] Corbin KS, Hellman S, Weichselbaum RR. Extracranial oligometastases: a subset of metastases curable with stereotactic radiotherapy. J Clin Oncol 2013;31:1384-90.

[7] Tree AC, Khoo VS, Eeles RA, et al. Stereotactic body radiotherapy for oligometastases. Lancet Oncol 2013;14:e28-37.

[8] Berkovic P, De Meerleer G, Delrue L, et al. Salvage stereotactic body radiotherapy for patients with limited prostate cancer metastases: deferring androgen deprivation therapy. Clin Genitourin Cancer 2013;11:27-32.

[9] Jereczek-Fossa BA, Fariselli L, Beltramo G, et al. Linac-based or robotic image-guided stereotactic radiotherapy for isolated lymph node recurrent prostate cancer. Radiother Oncol 2009;93:14-7.

[10] Ponti E, Ingrosso G, Carosi A, et al. Salvage stereotactic body radiotherapy for patients with prostate cancer with isolated lymph node metastasis: a single-center experience. Clin Genitourin Cancer 2015;13:e279-84.

[11] Moher D, Liberati A, Tetzlaff J, Altman DG, PRISMA Group. Preferred reporting items for systematic reviews and meta-analyses: the PRISMA statement. Ann Intern Med 2009;151:264-9.

[12] Casamassima F, Masi L, Menichelli C, et al. Efficacy of eradicative radiotherapy for limited nodal metastases detected with choline PET scan in prostate cancer patients. Tumori 2011;97:49-55.

[13] Jereczek-Fossa BA, Beltramo G, Fariselli L, et al. Robotic imageguided stereotactic radiotherapy, for isolated recurrent primary, lymph node or metastatic prostate cancer. Int J Radiat Oncol Biol Phys 2012;82:889-97.

[14] Ahmed KA, Barney BM, Davis BJ, Park SS, Kwon ED, Olivier KR. Stereotactic body radiation therapy in the treatment of oligometastatic prostate cancer. Front Oncol 2013;2:215.

[15] Decaestecker K, De Meerleer G, Lambert B, et al. Repeated stereotactic body radiotherapy for oligometastatic prostate cancer recurrence. Radiat Oncol 2014;9:135.

[16] Detti B, Bonomo P, Masi L, et al. Stereotactic radiotherapy for isolated nodal recurrence of prostate cancer. World J Urol 2015; 33:1197-203.

[17] Muldermans JL, Romak LB, Kwon ED, Park SS, Olivier KR. Stereotactic body radiation therapy for oligometastatic prostate cancer. Int J Radiat Oncol Biol Phys 2016;95:696-702.

[18] Pasqualetti F, Panichi M, Sainato A, et al. [(18)F]Choline PET/CT and stereotactic body radiotherapy on treatment decision making of oligometastatic prostate cancer patients: preliminary results. Radiat Oncol 2016;11:9.

[19] Ingrosso G, Trippa F, Maranzano E, et al. Stereotactic body radiotherapy in oligometastatic prostate cancer patients with isolated lymph nodes involvement: a two-institution experience. World J Urol 2017;35:45-9.

[20] Ost P, Jereczek-Fossa BA, Van As N, et al. Pattern of progression after stereotactic body radiotherapy for oligometastatic prostate cancer nodal recurrences. Clin Oncol (R Coll Radiol) 2016;28:e115-20.

[21] Cornford P, Bellmunt J, Bolla M, et al. EAU-ESTRO-SIOG guidelines on prostate cancer. Part II: treatment of relapsing, metastatic, and castration-resistant prostate cancer. Eur Urol 2017;71:630-42.

[22] Bauman G, Belhocine T, Kovacs M, Ward A, Beheshti M, Rachinsky I. 18F-fluorocholine for prostate cancer imaging: a systematic review of the literature. Prostate Cancer Prostatic Dis 2012;15:45-55.

[23] Mamede M, Ceci F, Castellucci P, et al. The role of 11C-choline PET imaging in the early detection of recurrence in surgically treated prostate cancer patients with very low PSA level $<0.5 \mathrm{ng} / \mathrm{mL}$. Clin Nucl Med 2013;38:e342-5.

[24] Shultz DB, Modlin LA, Jayachandran P, et al. Repeat courses of stereotactic radiosurgery (SRS), deferring whole-brain irradiation, 
for new brain metastases after initial SRS. Int J Radiat Oncol Biol Phys 2015;92:993-9.

[25] Rischke HC, Schultze-Seemann W, Wieser G, et al. Adjuvant radiotherapy after salvage lymph node dissection because of nodal relapse of prostate cancer versus salvage lymph node dissection only. Strahlenther Onkol 2015;191:310-20.

[26] Fodor A, Berardi G, Fiorino C, et al. Toxicity and efficacy of salvage carbon 11-choline positron emission tomography/computed tomography-guided radiation therapy in patients with lymph node recurrence of prostate cancer. BJU Int 2017;119:406-13.

[27] Würschmidt F, Petersen C, Wahl A, Dahle J, Kretschmer M. [18F] fluoroethylcholine-PET/CT imaging for radiation treatment planning of recurrent and primary prostate cancer with dose escalation to PET/CT-positive lymph nodes. Radiat Oncol 2011;6:44.

[28] Martorana G, Schiavina R, Franceschelli A. Should we perform imaging-guided lymph node dissection in patients with lymphatic recurrence of prostate cancer after radical prostatectomy? Eur Urol 2009;55:1302-4.

[29] Rigatti P, Suardi N, Briganti A, et al. Pelvic/retroperitoneal salvage lymph node dissection for patients treated with radical prostatectomy with biochemical recurrence and nodal recurrence detected by $[11 \mathrm{C}]$ choline positron emission tomography/computed tomography. Eur Urol 2011;60:935-43.

[30] Schick U, Jorcano S, Nouet P, et al. Androgen deprivation and highdose radiotherapy for oligometastatic prostate cancer patients with less than five regional and/or distant metastases. Acta Oncol 2013; 52:1622-8.

[31] Picchio M, Berardi G, Fodor A, et al. (11)C-Choline PET/CT as a guide to radiation treatment planning of lymph-node relapses in prostate cancer patients. Eur J Nucl Med Mol Imaging 2014;41:1270-9.

[32] Schwenck J, Rempp H, Reischl G, et al. Comparison of 68Ga-labelled PSMA-11 and 11C-choline in the detection of prostate cancer metastases by PET/CT. Eur J Nucl Med Mol Imaging 2017;44:92-101.

[33] Afshar-Oromieh A, Zechmann CM, Malcher A, et al. Comparison of PET imaging with a (68)Ga-labelled PSMA ligand and (18)Fcholine-based PET/CT for the diagnosis of recurrent prostate cancer. Eur J Nucl Med Mol Imaging 2014;41:11-20.
[34] Morigi JJ, Stricker PD, van Leeuwen PJ, et al. Prospective comparison of 18F-fluoromethylcholine versus 68Ga-PSMA PET/CT in prostate cancer patients who have rising PSA after curative treatment and are being considered for targeted therapy. J Nucl Med 2015; 56:1185-90.

[35] Perera M, Papa N, Christidis D, et al. Sensitivity, specificity, and predictors of positive 68Ga-prostate-specific membrane antigen positron emission tomography in advanced prostate cancer: a systematic review and meta-analysis. Eur Urol 2016;70:926-37.

[36] Lecouvet FE, El Mouedden J, Collette L, et al. Can whole-body magnetic resonance imaging with diffusion-weighted imaging replace Tc $99 \mathrm{~m}$ bone scanning and computed tomography for single-step detection of metastases in patients with high-risk prostate cancer? Eur Urol 2012;62:68-75.

[37] Pasoglou V, Michoux N, Peeters F, et al. Whole-body 3D T1weighted MR imaging in patients with prostate cancer: feasibility and evaluation in screening for metastatic disease. Radiology 2015; 275:155-66.

[38] Abdollah F, Briganti A, Montorsi F, et al. Contemporary role of salvage lymphadenectomy in patients with recurrence following radical prostatectomy. Eur Urol 2015;67:839-49.

[39] Birkhäuser FD, Studer UE, Froehlich JM, et al. Combined ultrasmall superparamagnetic particles of iron oxide-enhanced and diffusionweighted magnetic resonance imaging facilitates detection of metastases in normal-sized pelvic lymph nodes of patients with bladder and prostate cancer. Eur Urol 2013;64:953-60.

[40] Decaestecker K, De Meerleer G, Ameye F, et al. Surveillance or metastasis-directed Therapy for OligoMetastatic Prostate cancer recurrence (STOMP): study protocol for a randomized phase II trial. BMC Cancer 2014;14:671.

[41] US National Library of Medicine. ClinicalTrials.gov. https.//clinicaltrials.gov/ct2/show/NCT02680587 [2016].

[42] Supiot S, Rio E, Pacteau V, Mauboussin MH, Campion L, Pein F. OLIGOPELVIS - GETUG P07: a multicentre phase II trial of combined salvage radiotherapy and hormone therapy in oligometastatic pelvic node relapses of prostate cancer. BMC Cancer 2015;15:646. 